\title{
Solitary Esophageal Varix Simulating a Neoplasm
}

\author{
F.P. AGHA, M.D. \\ Department of Radiology \\ University of Michigan, Medical Center, Ann Arbor, Michigan 48109
}

A solitary esophageal varix simulating an esophageal tumor is reported. To my knowledge this rare entity has only been described once previously 1 .

\section{CASE REPORT}

A 57-year-old woman was referred to the University of Michigan Hospital in July 1984 for evaluation of iron deficiency anemia. She was transfused with five units of blood and then underwent complete evaluation of her gastrointestinal tract. During double contrast examination of her upper gastrointestinal tract a $2.0 \times 1.3 \mathrm{~cm}$ lobulated well demarcated polypoid lesion was found in the mid esophagus. This lesion was unaffected by esophageal distension (Figure 1). It was felt to be a benign lesion such as a fibrovascular polyp or a lipoma, however, malignancy could not be completely excluded. The remainder of the upper gastrointestinal tract and small bowel follow through was normal except for a small hiatal hernia. An air contrast barium enema was unremarkable. Endoscopic examination of the esophagus revealed a sausage shaped lobulated $2.1 \mathrm{x} 1 \mathrm{~cm}$ firm submucosal mass in the mid esophagus with normal overlying mucosa. It had the bluish tinge of an ectatic venous structure. The diagnosis of a thrombosed esophageal varix was made. To completely exclude the possibility of a neoplasm a mucosal biopsy was performed which was normal at histopathologic examination. Colonscopy revealed large internal hemorrhoids and no other abnormalities. A chest CT examination did not reveal any mediastinal abnormalities. The esophageal varix was not seen. There was no evidence of portal hypertension or liver disease.

\footnotetext{
Address for reprints:

Faroog P. Agha, M.D.

Department of Radiology - Box 013

University Hospital

1405 East Ann Street

Ann Arbor, Michigan 48109
}

It was felt that source of this patient's chronic gastrointestinal blood loss was large internal hemorrhoids. She was discharged and subsequently underwent an elective hemorrhoidectomy. Her clinical course was satisfactory. Follow-up endoscopic examinations at 6 and 12 months have revealed no change in the appearance of the solitary thrombosed esophageal varix.

\section{DISCUSSION}

The typical esophageal varices are characterized by their multiplicity, orad orientation in the distal half of the esophagus and the clinical setting of portal hypertension. On the basis of etiology esophageal varices may be classified into congenital or acquired. In a detailed review of the subject, Jorup 2 found that only two or three authentic cases of congenital esophageal varices have been reported in the world literature up to 1948 . Harinck, et $\mathrm{al}^{3}$ in 1971 reported congenital esophageal varices in identical twins without portal hypertension.

The acquired varices are most commonly due to portal hypertension. The common intrahepatic causes of portal hypertension consist of alcoholic cirrhosis, cryptogenic cirrhosis, hepatic cirrhosis associated with hepatocellular carcinoma, congenital hepatic fibrosis, chronic active hepatitis, biliary cirrhosis, Wilson's disease, hepatic vein thrombosis and obstruction, hemochromatosis and galactosemia. The extrahepatic causes of portal hypertension consist of portal vein atresia, stenosis, cavernous malformation and thrombosis, compression of portal vein by tumor, cyst or nodes, arterioportal fistula related to trauma and pancreatitis. Some rare causes include schistosomiasis, alpha I - antitryspin deficiency and methotrexate induced hepatic fibrosis 4 . In most esophageal varices due to portal hypertension, the blood flow is "uphill" towards the superior vena cava and azygos vein. Esophageal varices are occasionally found in patients without portal

Accepted for publication on 14th July, 1988. 


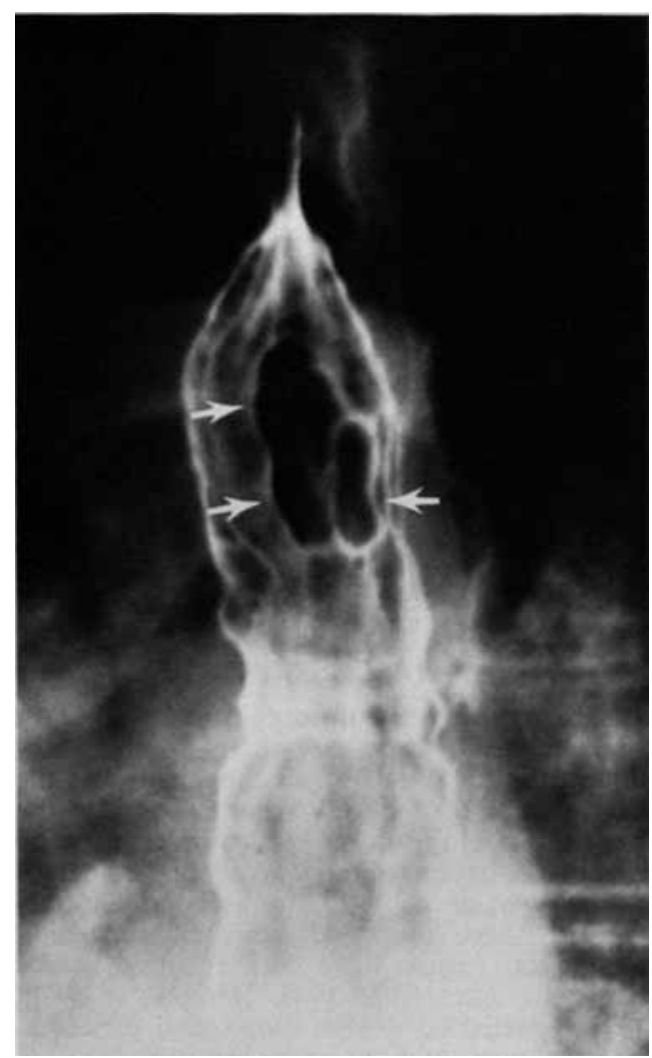

FIGURES 1A and 1B - Two views from a double contrast esophagram show a lobulated sausage shaped, sharply demarcated mass (arrows) in the mid esophagus representing a solitary varix.

hypertension. These are so called "downhill" varices found in the upper esophagus and are most commonly due to obstruction of the superior vena cava or azygos vein by neoplastic processes of the mediastinum, retrosternal goitre, thymoma and mediastinal fibrosis 5 .

A solitary esophageal varix without underlying portal hypertension, superior vena cava or azygos venous obstruction is extremely rare. Its presentation as esophageal mass has only been reported once previously .

The typical esophageal varices are distinguished radiographically as multiple serpiginous filling defects which can be effaced by distension of the esophagus during double contrast esophagram. This feature may be seen in a solitary varix without any thrombosis, however,

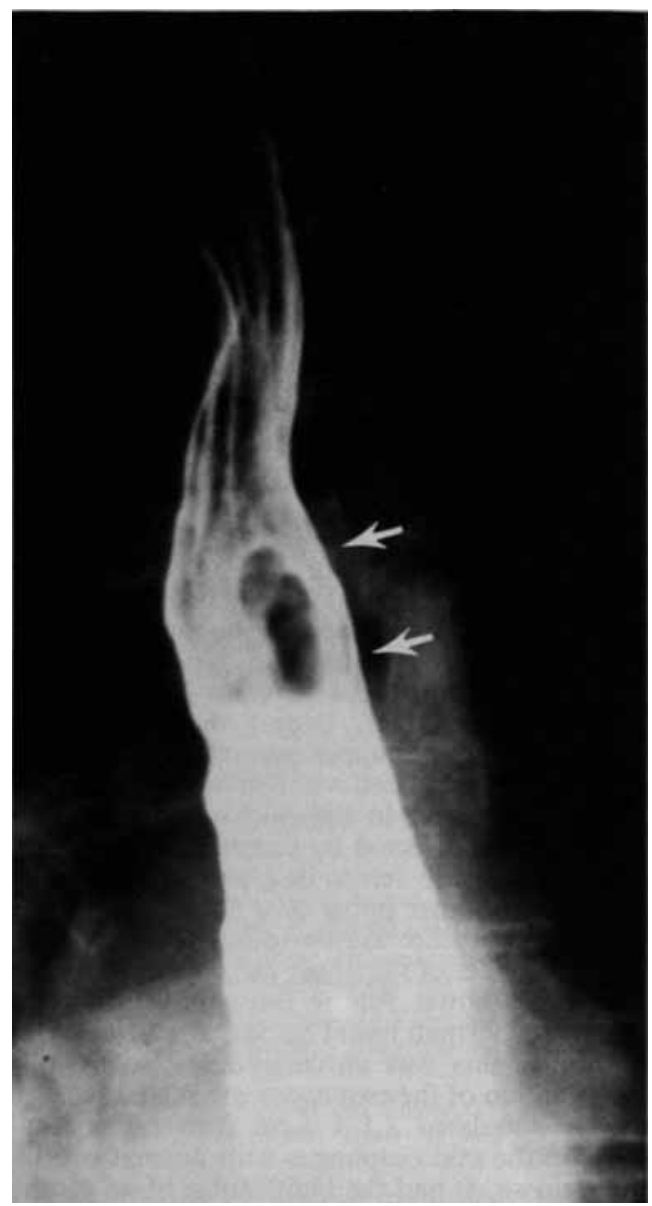

a thrombosed varix does not show obliteration by distension of the esophageal lumen 1 . Of the two cases reported previously, one did and the other did not, show obliteration of the varix when the esophagus was distended. In the present case the polypoid lobulated mass did not change in size, shape or configuration during double contrast esophagram.

The incidence of solitary esophageal varix is not known. The congenital esophageal varices 2,3 and idiopathic esophageal varices6-9 are also reported to be quite rare. Garrett and Gall 8 in a series of 18,000 autopsies found only $3 \%$ incidence of idiopathic esophageal varices. None of the standard texts and major reviews pertaining to esophageal diseases and portal hypertension mention about solitary esophageal varix $4,6,10-14$. 


\section{SOLITARY ESOPHAGEAL VARIX SIMULATING A NEOPLASM}

The mechanism of development of a solitary varix is not known. It has been postulated that congenital weakness of the wall of venous channels might be responsible7,8,15. In three cases of idiopathic solitary esophageal varix reported thus far (including the present case), the varix was located in the mid esophageal region, ranging in size from $1-2 \mathrm{~cm}$ with typical submucosal location. Two were thrombosed and one without thrombosis.

The most common differential diagnosis of solitary esophageal varix should include benign intramural tumors, esophageal cyst (retension cyst or foregut respiratory cyst) and localized hematoma. The intramural and submucosal tumors of the esophagus which constitute the usual differential diagnosis of a solitary esophageal varix are leiomyoma, lipomas, granular cell myoblastoma, fibroma, hemangioma, neurofibroma and carcinoid ${ }^{16-9}$. An aberrant pancreatic rest 6 and aberrant thyroid 14 may also present as intramural lesions. The intramural lesions are usually asymptomatic until they are large enough to compromise the lumen to produce dysphagia. Although carcinoma of the esophagus, esophageal lymphoma and metastatic tumors to the esophagus may present as submucosal mass $20-22$, the associated clinical setting and other radiographic finding are helpful in arriving at a correct diagnosis.

The present case is quite unique, because despite its unchanged radiographic appearance at double contrast esophagram, the endoscopy revealed characteristic submucosal location, bluish tinge and ectatic venous structure. The diagnosis of a non-thrombosed solitary varix can be suggested with confidence at esophagram. The thrombosed varix presents a diagnostic challenge and difficult to diagnose short of skillful endoscopy or surgery. Awareness of this entity and familiarity with its radiographic and endoscopic features are a prerequisite for arriving at a correct diagnosis.

\section{ACKNOWLEDGEMENT}

The author thanks Ms. Barbara Smith for excellent secretarial assistance and Timothy T. Nostrant, M.D. who performed the endoscopic examination.

\section{REFERENCES}

1. Trenkner SW, Levine MS, Laufer I and Glick SN. Idiopathic Esophageal Varix. Amer J Roentgen 1983; $141: 43-44$.

2. Jorup S. Congenital Varices of the Esophagus. Acta Paediatr (Stockh) 1948; $35: 247-257$.

3. Harinck E, Fernandes $J$ and Vervat D. Congenital Esophageat-Varices in Identical Twins Without Portal Hypertension. J Pediatr Surg 1971; 6 : 488.

4. Child CG 3rd. Portal Hypertension: As Seen by 17 Authorities. Major Prob in Current Surv Vol. 24, 1974; Philadelphia 1974, W.B. Saunders Co. Publishers.

5. Felson B and Lessure AP: "Downhill Varices" of the Esophagus. Dis Chest 1964; $46: 740-746$.

6. Brombart M. Clinical Radiology of Oesophagus. Brombart M (Ed), Bristol 1961, John Wright and Sons Ltd, Publishers. 325-340.

7. Kelsen $K$ and Burbige EJ. Idiopathic Esophageal Varices. Amer J Gastroenterol 1982; 77 : 539-540.

8. Garrett $\mathrm{N}$ and Gall E. Esophageal Varices Without Hepatic Cirrhosis. Arch Pathol 1953; 55 : 196-202.

9. Schaefer J, Bramschreiber J, Mistilis S and Schiff L. Gastroesophageal Variceal Bleeding in the Absence of Hepatic Cirrhosis or Portal Hypertension. Gastroenterology 1964; $46: 583-588$.

10. Vlades-Dapena $A M$ and Stein GN. Morphologic Pathology of the Alimentary Canal. Vlades-Dapena $A M$ and Stein GN (Eds) Philadelphia, 1970; W.B. Saunders Co. Publishers. 2-107.

11. Payne WS and Olsen AM. The Esophagus. Payne WS and Olsen AM (Eds) Philadelphia, 1974; Lee and Febiger, Publishers. 225-238 and 273-304.
12. Enterline HS and Thompson JJ. Pathology of the Esophagus. Enterline $H S$ and Thompson JJ (Eds) New York, 1984; Springer Verlag, New York Inc. Publishers.

13. Palmer ED. The Esophagus and Its Diseases. Palmer ED (Ed), New York, 1952; Harper and Row, Publishers.

14. Terracol J and Sweet RH. Diseases of the Esophagus, Terracol $J$ and Sweet RH (Eds) Philadelphia, 1958; W.B. Saunders Co. Publishers.

15. Friedman E. Esophageal Varix. Report of a Case in a Three and One Half Year Old Child, Not Dependent on Liver Cirrhosis. J Pediatr 1934; 4 : 641-647.

16. Plachta A. Benign Tumor of the Esophagus. Review of Literature and Review of 99 Cases. Amer I Roentgenol $1962 ; 38: 639-652$.

17. Gallin FJ. Intramural Lesions of Esophagus. JAMA 1968; $204: 1065-1066$.

18. Attah EB and Hajdu SI. Benign and Malignant Tumors of the Esophagus at Autopsy. I Thorac Cardiovasc Surg 1968; $55: 396-404$.

19. Brenner $S$, Heimlich $H$ and Widman $M$. Carcinoid of Esophagus. N.Y. State J Med 1969; 19 : 1337-1339.

20. Agha FP and Whitehouse WM. Carcinorna of the Esophagus. It's Varied Radiologic Features. Mt Sinai J Med (N.Y.) 1984; 51 : 430-441.

21. Agha FP and Schnitzer B. Esophageal Involvement by Lymphoma. Am J Gastroenterol 1985; $80: 412-416$.

22. Agha FP. Barrett Carcinoma of the Esophagus. Clinical and Radiographic Analysis of 34 Cases. Amer J Roentgen 1985; $145: 41-46$. 